\title{
Effect of selenium deficiency on hydroperoxide-stimulated release of glutathione from isolated perfused liver of rainbow trout (Salmo gairdneri)
}

\author{
BY J. G. BELL, J. W. ADRON AND C. B. COWEY \\ NERC Institute of Marine Biochemistry, St Fittick's Road, Aberdeen ABI $3 R A$
}

(Received 2 December 1985 - Accepted 10 April 1986)

\begin{abstract}
1. Duplicate groups of rainbow trout (Salmo gairdneri) were each given partially purified diets which were either adequate or depleted in selenium for $\mathbf{4 0}$ weeks.

2. Although there was no significant difference in weight gain, liver Se concentration was significantly lower in fish given the deficient diet.

3. Glutathione (GSH) peroxidase (EC 1.11.1.9) activity was significantly reduced in liver of Se-deficient fish but a differential assay did not indicate the presence of a non-Se-dependent GSH peroxidase activity, although liver GSH S-transferase (EC 2.5.1 .18) was significantly increased.

4. Perfusion of livers from trout given Se-adequate diets with $t$-butyl hydroperoxide (BuOOH) or hydrogen peroxide caused an increase in the rate of release of glutathione disulphide (GSSG) into the perfusate.

5. Perfusion of livers from Se-deficient trout with $\mathrm{BuOOH}$ or $\mathrm{H}_{2} \mathrm{O}_{2}$ did not result in any change in rate of release of GSSG into the perfusate.

6. These findings confirm the absence of any compensatory non-Se-dependent peroxidase activity in Se-depleted trout.
\end{abstract}

Selenium deficiency in mammals is known to increase the activity of the glutathione S-transferase (EC 2.5.1.18) group of enzymes (Lawrence et al. 1978). A number of these enzymes also possess peroxidase activity (the so-called Se-independent glutathione peroxidase activity; Prohaska \& Ganther, 1977) with organic hydroperoxides but not with hydrogen peroxide. This activity is maintained in Se deficiency. In mammals this system is thought to protect against oxidative damage when Se-dependent glutathione (GSH) peroxidase $(E C 1.11 .1 .9)$ is depleted during Se deficiency.

In rainbow trout (Salmo gairdneri) which have been depleted of Se there is no detectable Se-independent GSH peroxidase activity, although liver GSH S-transferase activity showed a marked increase (Bell et al. 1986b). Semi-purified trout liver GSH S-transferase has also been shown to inhibit the production of malondialdehyde in an in vitro microsomal lipid peroxidation system (Bell et al. 1984).

The present investigation was performed in order to identify further the role of GSH S-transferase in preventing lipid peroxidation in rainbow trout liver.

Perfusion of livers from control and Se-deficient rats with media containing organic hydroperoxides or $\mathrm{H}_{2} \mathrm{O}_{2}$ have clarified and confirmed the function of the Se-dependent and Se-independent GSH peroxidases in hydroperoxide metabolism. In control animals glutathione disulphide (GSSG) efflux from the liver increased in response to administration of either $t$-butyl hydroperoxide $(\mathrm{BuOOH})$ or $\mathrm{H}_{2} \mathrm{O}_{2}$ used independently; by contrast, in Se-deficient animals, GSSG efflux only increased when an organic hydroperoxide was perfused (Burk et al. 1979). However, in studies involving isolated perfused rat heart (Xia et al. 1985) from Se-deficient animals, no GSSG efflux was observed on perfusion with BuOOH indicating that GSH-dependent hydroperoxide metabolism does not occur in the Se-deficient rat heart.

In the present study with rainbow trout we have studied GSH-dependent hydroperoxide metabolism in control and Se-deficient isolated perfused livers in an attempt to characterize 
the antioxidant processes occurring in rainbow trout and to assess impairment due to $\mathrm{Se}$ deficiency. A preliminary account of this work has been given (Bell et al. 1986a).

\section{MATERIALS AND METHODS \\ Animals and diets}

Rainbow trout were obtained from Selcoth Fisheries, Moffat, Scotland; they had a mean weight of approximately $27 \mathrm{~g}$ and they were randomly distributed (thirty fish/tank) between four fibre glass tanks of diameter $1 \mathrm{~m}$ and depth $0.6 \mathrm{~m}$, and containing 500 litres of water. The water, from Aberdeen city domestic supply, passed through an activated charcoal filter to the tanks with a total flow to each tank of 10 litres $/ \mathrm{min}$. The ambient temperature in the aquarium room averaged $15^{\circ}$ and the photoperiod was $12 \mathrm{~h}$ light-12 $\mathrm{h}$ dark.

The fish were weaned from a commercial diet to the basal diet (Se-deficient) (Bell et al. $1986 \mathrm{~b}$ ) and about 1 week later initial weight measurements were made on individual fish which had been anaesthetized with MS222 (ethyl $m$-aminobenzoate methane sulphonate; Sigma Chemical Co. Ltd, Poole, Dorset; $0 \cdot 2 \mathrm{~g} / \mathrm{l}$ ). Fish were fed at a rate of $20 \mathrm{~g} / \mathrm{kg}$ biomass per $\mathrm{d}$ (the diet being given four or five times per day), $6 \mathrm{~d}$ each week. Any food uneaten from the daily ration was weighed and recorded. Fish were weighed at $28 \mathrm{~d}$ intervals and the ration adjusted accordingly. The growth experiment lasted 30 weeks. Thereafter fish continued to be fed at the same rate for a further 30 weeks when they had attained a size suitable for liver perfusion, i.e. about $400 \mathrm{~g}$.

The basal diet (Se-deficient) contained Torula yeast and was designed to meet the nutritional requirements of trout other than for Se ((US) National Research Council, 1981). The basal diet formulation (Table 1) and preparation were as described previously (Bell et al. 1986 b). The control diet (Se-supplemented) had Se added as sodium selenite to $1 \mathrm{mg} / \mathrm{kg}$. The basal diet contained 0.025 (SE 0.004) $\mathrm{mg} \mathrm{Se} / \mathrm{kg}$ and 0.63 (SE 0.06) $\mathrm{g}$ vitamin $\mathrm{E} / \mathrm{kg}$. The aquarium water contained $0.035 \mu \mathrm{g} \mathrm{Se} / 1$. Each of the two diets was given to duplicate groups (tanks) of fish. Feed : gain values were calculated at each weighing on a per tank basis as total diet consumed : total increase in biomass.

\section{Liver perfusion}

Rainbow trout were anaesthetized with MS222 and injected with 100 units lithium heparin (in isotonic saline ( $9 \mathrm{~g}$ sodium chloride/1)) via the caudal vein. After $15 \mathrm{~min}$ the fish were killed by a blow to the head. The liver was cannulated via the hepatic portal vein (Portex green luer 2FG; Portex Ltd, Hythe) then rapidly excised and mounted on a recirculating perfusion apparatus similar to that described by Hayashi \& Ooshiro (1975). The average liver weight was 7.43 (SE 0.83 ) g. The perfusion medium, which was a glucose-free Hanks medium, $\mathrm{pH} 7 \cdot 4$, contained: $112 \mathrm{~mm}-\mathrm{NaCl}, 4 \cdot 2 \mathrm{~mm}$-potassium chloride, $0 \cdot 1 \mathrm{~mm}$-ammonium sulphate, 26.2 mm-sodium bicarbonate, $1.0 \mathrm{~mm}$-disodium hydrogenphosphate, $1.3 \mathrm{~mm}$ calcium chloride, $1.2 \mathrm{~mm}$-magnesium sulphate, $2 \cdot 1 \mathrm{~mm}$-lactic acid, $0 \cdot 3 \mathrm{~mm}$-pyruvic acid, 5 mM-HEPES, $0.17 \mathrm{~mm}$-histidine, $0.07 \mathrm{~mm}$-aspartic acid, $0.12 \mathrm{~mm}$-glutamic acid. It was perfused at a rate of $1.3 \mathrm{ml} / \mathrm{g}$ per min and at a temperature of $20 \pm 2^{\circ}$. The medium was continuously oxygenated with oxygen-carbon dioxide $(95: 5, \mathrm{v} / \mathrm{v})$. After an initial $15 \mathrm{~min}$ perfusion where effluent was allowed to run to waste, recirculation was started and the volume of perfusion medium adjusted to $50 \mathrm{ml}$. After a further $10 \mathrm{~min}$ perfusion the zero time sample $(0.6 \mathrm{ml})$ was taken and after $10 \mathrm{~min}$ the medium was made either $1 \mathrm{~mm}$ in BuOOH or $2 \mathrm{mM}$ in $\mathrm{H}_{2} \mathrm{O}_{2}$ by addition to the media reservoir. Samples $(0.6 \mathrm{ml})$ were collected post aerator every $10 \mathrm{~min}$ up to $90 \mathrm{~min}$ and were assayed for total glutathione (GSH+GSSG), hydroperoxide content and lactate dehydrogenase (EC 1.1.1.27) activity. 
Table 1. Composition of basal diet ( $\mathrm{g} / \mathrm{kg} d r y$ diet)

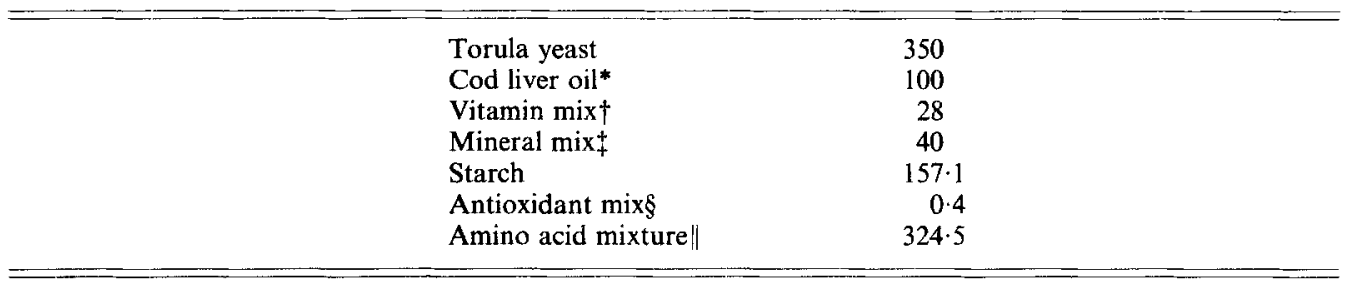

* Super Solvitax; British Cod Liver Oils Ltd, Hull.

† Supplied (/kg diet): thiamin hydrochloride $50 \mathrm{mg}$, riboflavin $200 \mathrm{mg}$, pyridoxine hydrochloride $50 \mathrm{mg}$, nicotinic acid $750 \mathrm{mg}$, calcium pantothenate $500 \mathrm{mg}$, myo-inositol $2 \mathrm{~g}$, biotin $5 \mathrm{mg}$, folic acid $15 \mathrm{mg}$, choline bitartrate $9 \mathrm{~g}$, ascorbic acid $1 \mathrm{~g}$, menaphthone $40 \mathrm{mg}$, cyanocobalamin $0.09 \mathrm{mg}$, DL- $\alpha$-tocopheryl acetate $400 \mathrm{mg}$.

† Supplied (g/kg diet): $\mathrm{Ca}\left(\mathrm{H}_{2} \mathrm{PO}_{4}\right)_{2} \cdot \mathrm{H}_{2} \mathrm{O} 27 \cdot 6, \mathrm{CaCO}_{3} 2 \cdot 1, \mathrm{MgCO}_{3} 3 \cdot 6, \mathrm{FeSO}_{4} \cdot 7 \mathrm{H}_{2} \mathrm{O} \cdot \cdot 2, \mathrm{KCl} 2 \cdot 0, \mathrm{NaCl} 3 \cdot 2$, $\mathrm{Al}_{2}\left(\mathrm{SO}_{4}\right)_{3} .16 \mathrm{H}_{2} \mathrm{O} 0.008, \mathrm{ZnSO}_{4} .7 \mathrm{H}_{2} \mathrm{O} 0 \cdot 16, \mathrm{CuSO}_{4} 0.04, \mathrm{MnSO}_{4} .4 \mathrm{H}_{2} \mathrm{O} 0 \cdot 14, \mathrm{KI} 0.008, \mathrm{CoSO}_{4} 0.04$.

$\S$ Contained (g/l): 200 butylated hydroxyanisole, 60 propyl gallate and 40 citric acid dissolved in propylene glycol.

|| Supplied ( $\mathrm{g} / \mathrm{kg}$ diet): lysine 32 , histidine $12 \cdot 2$, arginine $21 \cdot 6$, threonine 14.6 , valine $15 \cdot 8$, methionine 6 , isoleucine $13 \cdot 6$, leucine $28 \cdot 3$, phenylalanine $13 \cdot 2$, tryptrophan $4 \cdot 3$, aspartic acid $32 \cdot 1$, serine $15 \cdot 9$, glutamic acid 50 , proline $12 \cdot 2$, glycine $14 \cdot 9$, alanine $21 \cdot 7$, tyrosine $11 \cdot 3$, cystine $4 \cdot 8$.

\section{Analytical methods}

Total glutathione (GSH + GSSG) in the perfusate was determined by the glutathione reductase-DTNB (5,5'-dithiobis-(2-nitrobenzoic acid)) recirculating assay described by Oshino \& Chance (1977). GSSG was determined by measuring NADPH oxidation in the presence of glutathione reductase $(\mathrm{NAD}(\mathrm{P}) \mathrm{H})(E C$ 1.6.4.2) as described by Sies \& Summer (1975). Se in tissues and aquarium water was measured by the method of Hasunuma et al. (1982). GSH peroxidase was measured by following the rate of oxidation of NADPH at $340 \mathrm{~nm}$ in the coupled reaction with GSH reductase as described by Bell et al. $(1986 \mathrm{~b})$ and GSH S-transferase activity was assayed by following the conjugation of 1-chloro-2,4-dinitro-benzene with GSH at $340 \mathrm{~nm}$ (Habig et al. 1974). Lactate dehydrogenase in the perfusate was measured by following the oxidation of NADH at $340 \mathrm{~nm}$ as described by Lush et al. (1969). The assay contained (final concentrations): $87 \mathrm{~mm}$ potassium phosphate buffer, $\mathrm{pH} 7.4,0.09 \mathrm{~mm}$-sodium pyruvate and $0.15 \mathrm{~mm}-\mathrm{NADH}$. The reaction was started by addition of up to $0.2 \mathrm{ml}$ of enzyme source. Perfusate hydroperoxide was measured by the method described by Cathcart et al. (1983).

\section{Statistical analysis}

The initial and final weight measurements on the trout in all four tanks were examined by analysis of variance as described by Bell et al. (1980 b).

\section{RESULTS}

Initial and final weights of trout given the two diets are shown in Table 1 and there were no significant differences in weight gain in any of the tanks.

Se concentrations in liver were very markedly reduced in trout fed on the Se-deficient diet (Table 2) and reflecting this liver GSH peroxidase activity was similarly reduced (Table 2). The differential assay performed with either $\mathrm{H}_{2} \mathrm{O}_{2}$ or organic hydroperoxide did not provide convincing evidence for the appearance of a non-Se-dependent GSH peroxidase as a result of Se deficiency, although there was a significant increase in liver GSH S-transferase activity (Table 2). 
Table 2 Weight gain values, liver selenium and some liver enzyme activities in rainbow trout (Salmo gairdneri) fed on diets either supplemented or deficient in Se

(Mean values with their standard errors)

\begin{tabular}{|c|c|c|c|c|c|c|c|c|}
\hline \multirow[t]{3}{*}{ Diet... } & \multicolumn{4}{|c|}{$-\mathrm{Se}$} & \multicolumn{4}{|c|}{$+\mathrm{Se}$} \\
\hline & \multicolumn{2}{|c|}{ A } & \multicolumn{2}{|c|}{ B } & \multicolumn{2}{|c|}{$\mathrm{C}$} & \multicolumn{2}{|c|}{ D } \\
\hline & Mean & SE & Mean & SE & Mean & SE & Mean & $\mathrm{SE}$ \\
\hline Initial wt $(\mathrm{g})$ & $25 \cdot 70$ & $1 \cdot 24$ & $26 \cdot 34$ & $1 \cdot 74$ & $26 \cdot 57$ & $2 \cdot 01$ & $28 \cdot 12$ & $2 \cdot 11$ \\
\hline Final wt (g) & $144 \cdot 46$ & $8 \cdot 47$ & $155 \cdot 94$ & $12 \cdot 76$ & $159 \cdot 37$ & $10 \cdot 63$ & 163.87 & 9.62 \\
\hline \multirow[t]{2}{*}{ Feed : gain } & \multicolumn{2}{|c|}{1.71} & \multicolumn{2}{|c|}{1.61} & \multicolumn{2}{|c|}{$1 \cdot 54$} & \multicolumn{2}{|c|}{$1 \cdot 50$} \\
\hline & \multicolumn{2}{|c|}{ Mean } & \multicolumn{2}{|c|}{$\mathrm{SE}$} & \multicolumn{2}{|c|}{ Mean } & \multicolumn{2}{|c|}{$\mathrm{SE}$} \\
\hline $\begin{array}{l}\text { Liver } \mathrm{Se}(\mu \mathrm{g} / \mathrm{g} \\
\text { wet tissue) } \\
\text { Liver } \mathrm{GSH} \text { peroxidase }(E C 1.11\end{array}$ & \multicolumn{2}{|c|}{$0 \cdot 122$} & \multicolumn{2}{|c|}{0.019} & \multicolumn{2}{|c|}{$1 \cdot 321$} & \multicolumn{2}{|c|}{$0 \cdot 258$} \\
\hline Hydrogen peroxide substrate* & \multicolumn{2}{|c|}{$2 \cdot 50$} & \multicolumn{2}{|c|}{$0 \cdot 68$} & \multicolumn{2}{|c|}{$14 \cdot 38$} & \multicolumn{2}{|c|}{1.83} \\
\hline $\begin{array}{l}\text { Cumene hydroperoxide } \\
\text { substrate } \dagger\end{array}$ & \multicolumn{2}{|c|}{$5 \cdot 05$} & \multicolumn{2}{|c|}{0.85} & \multicolumn{2}{|c|}{$18 \cdot 60$} & \multicolumn{2}{|c|}{$1 \cdot 72$} \\
\hline $\begin{array}{l}\text { Liver GSH S-transferase } \\
(E C 2.5 .1 .13)_{\ddagger}^{\ddagger}\end{array}$ & \multicolumn{2}{|c|}{0.713} & \multicolumn{2}{|c|}{0.072} & \multicolumn{2}{|c|}{$0 \cdot 311$} & \multicolumn{2}{|c|}{0.034} \\
\hline
\end{tabular}

$A$ and $B$ are duplicate tanks, $C$ and $D$ are duplicate tanks.

* nmol NADPH oxidized/min per $\mathrm{mg}$ protein, $0.25 \mathrm{~mm}-\mathrm{H}_{2} \mathrm{O}_{2}$ substrate.

$\dagger$ nmol NADPH oxidized/min per $\mathrm{mg}$ protein, $1.5 \mathrm{~mm}$-cumene hydroperoxide substrate.

$\ddagger \mu \mathrm{mol}$ thioester bond formed/min per $\mathrm{mg}$ protein.

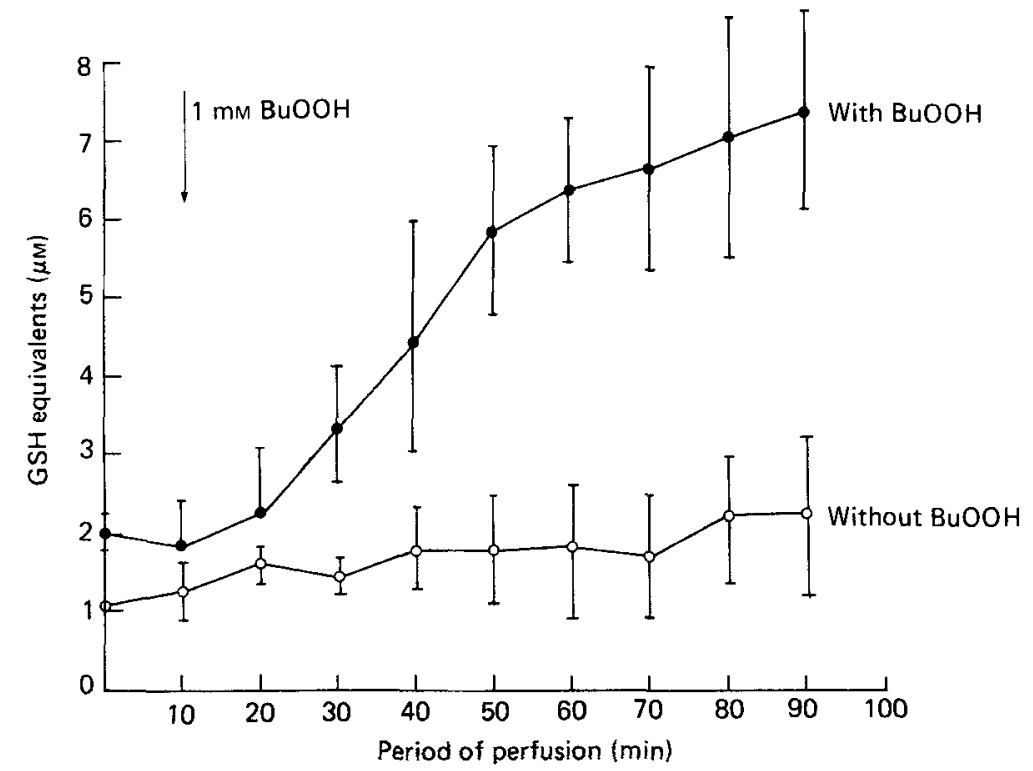

Fig. 1. Glutathione disulphide release (glutathione (GSH) equivalents) from isolated perfused liver of rainbow trout (Salmo gairdneri) fed on a control diet in the presence $\left(O_{-}\right)$or absence $(\mathrm{O}-\mathrm{O})$ of $1 \mathrm{~mm}$ - $t$-butyl hydroperoxide $(\mathrm{BuOOH})$. Points are mean values, with their standard errors represented by vertical bars, from three livers. 


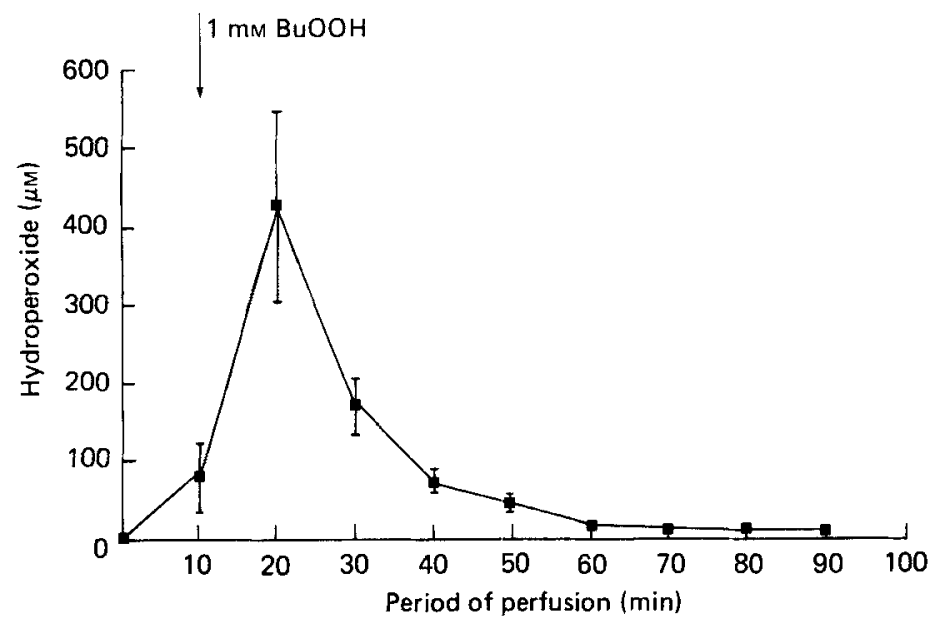

Fig. 2. Uptake of $t$-butyl hydroperoxide (BuOOH) by isolated perfused liver of rainbow trout (Salmo gairdneri) fed on a control diet. Points are mean values, with their standard errors represented by vertical bars, from three livers.

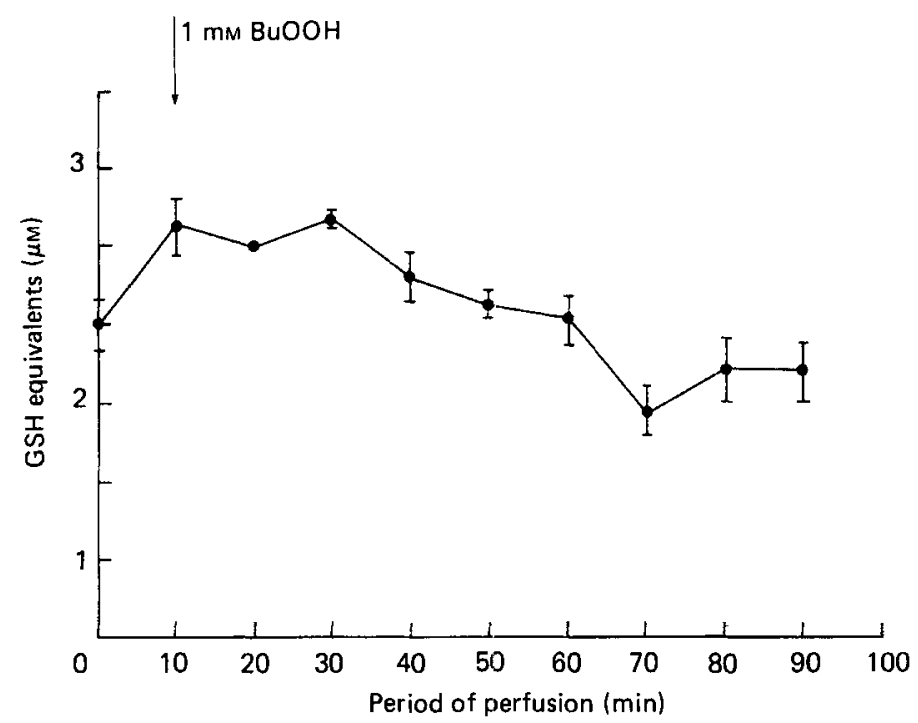

Fig. 3. Glutathione disulphide release (glutathione (GSH) equivalents) from isolated perfused liver of rainbow trout (Salmo gairdneri) fed on a selenium-deficient diet : effect of addition of $t$-butyl hydroperoxide $(\mathrm{BuOOH})$ to the perfusion medium. Points are mean values, with their standard errors represented by vertical bars, from three livers.

Fig. 1 shows the effect of infusing $\mathrm{BuOOH}$ into a control liver. Although the assay employed measured 'GSH equivalents' (i.e. total GSH) the nature of GSH released on perfusion of hydroperoxide was found to be entirely as the disulphide. After a short lag-period release of GSSG into the perfusate proceeded at a steady rate for $50 \mathrm{~min}$, thereafter there was some reduction in rate of GSSG release. The slowing down of GSSG release occurred when approximately $95 \%$ of the $\mathrm{BuOOH}$ had been removed from the perfusion medium (see Fig. 2). No major cell damage occurred over this period since lactate dehydrogenase measurements indicated only a small rise in this activity over the $90 \mathrm{~min}$ 


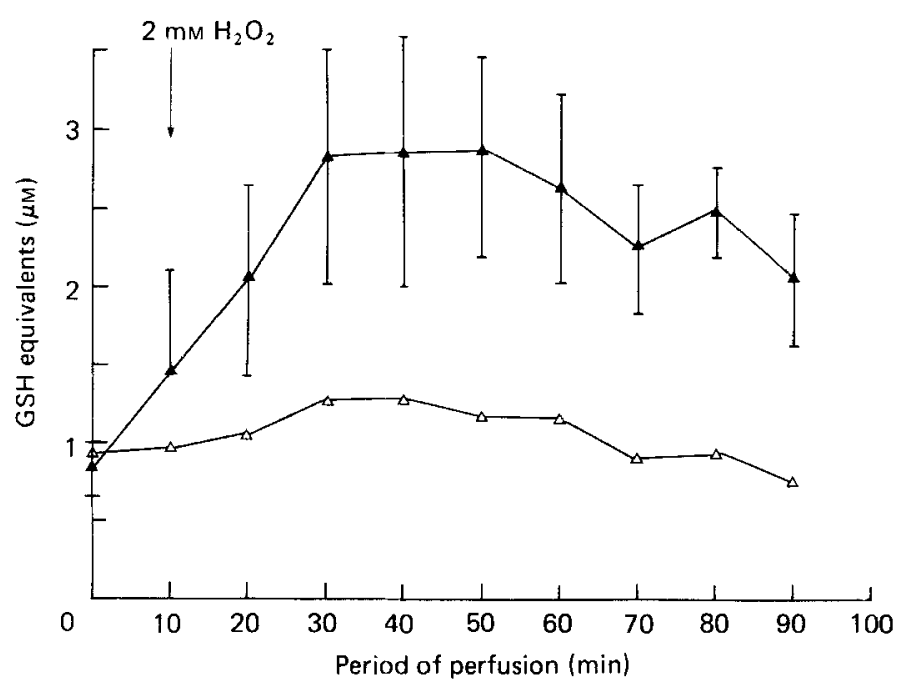

Fig. 4. Glutathione disulphide release (glutathione (GSH) equivalents) from isolated perfused liver of rainbow trout (Salmo gairdneri) fed on a control diet $(\mathbf{\Delta}-\mathbf{\Delta})$ or a selenium-deficient $\operatorname{diet}(\triangle-\triangle)$ when hydrogen peroxide was added to the perfusion medium. In the control fish, points are mean values, with their standard errors represented by vertical bars, from three livers. In Se-deficient fish points are mean values from two livers. The third Se-deficient liver showed high initial lactate dehydrogenase $(E C$ 1.1.1.27) release which increased fourfold over $90 \mathrm{~min}$. The values from this experiment were not used here.

period (results not shown). Release of GSSG from a control liver perfused in the absence of $\mathrm{BuOOH}$ was very low (Fig. 1).

When livers from Se-deficient trout were perfused with BuOOH no increase in GSSG release was observed (Fig. 3), although the initial levels of GSSG in the perfusion medium appeared greater than in control fish (Fig. 1). BuOOH was taken up by Se-deficient liver (results not shown) with a profile similar to that seen in control fish (Fig. 2) but this was not followed by a GSH-dependent metabolism of $\mathrm{BuOOH}$ as occurred in the control liver.

When $\mathrm{H}_{2} \mathrm{O}_{2}$ was added to the medium perfusing control livers there was an increased release of GSSG into the perfusate (Fig. 4) but this efflux levelled off after about $30 \mathrm{~min}$. Infusion of $\mathrm{H}_{2} \mathrm{O}_{2}$, as with $\mathrm{BuOOH}$, failed to cause a release of GSSG when Se-deficient livers were used.

\section{Discussion}

The presence of non-Se-dependent GSH peroxidase activity has been confirmed in the tissues of a number of different species (Lawrence \& Burk, 1978). This activity has been attributed to one or more of the GSH S-transferase enzymes identified in rat liver (Meyer et al. 1985). In the present study Se-deficient rainbow trout showed an increased hepatic GSH S-transferase activity similar to that in Se-deficient rats (Lawrence et al. 1978), although this was not reflected in an increased GSH peroxidase activity as measured by differential assay. The ability of Se-deficient rat liver to undergo GSH-dependent metabolism of organic hydroperoxides has been confirmed in studies with isolated perfused preparations (Sies \& Summer, 1975; Burk et al. 1978). In perfused liver of Se-deficient rainbow trout, however, no release of GSSG into the perfusing medium occurred when either $\mathrm{H}_{2} \mathrm{O}_{2}$ or $\mathrm{BuOOH}$ were added to the system. This result, which contrasts with that in normal control trout, confirms the enzyme findings in that no compensatory increase of non-Se-dependent 
GSH peroxidase activity is present when GSH peroxidase activity is reduced due to Se deficiency.

Although the infusion of $\mathrm{H}_{2} \mathrm{O}_{2}$ into control livers produced an increased GSSG release into the perfusate the duration of release was shorter and the maximum concentration reached was lower than that with $\mathrm{BuOOH}$ (Fig. 4). A similar effect was noted by Sies \& Summer (1975) and was thought to be due to the intervention of catalase $(E C 1.11 .1 .6)$ acting to remove $\mathrm{H}_{2} \mathrm{O}_{2}$, so preventing its reduction by $\mathrm{GSH}$ peroxidase.

In some Se-deficient livers, particularly those perfused with $\mathrm{BuOOH}$, a relatively high resting state release of GSSG was observed. This effect had been described previously in rat liver (Burk et al. 1978) and had been suggested as an indication of a higher incipient rate of lipid peroxidation occurring in Se-deficient liver (Nishiki et al. 1976).

The differences between trout and mammalian GSH S-transferases that affect their ability to act as a GSH-peroxidase are not clear. Possibly the Se-deficiency in trout is not severe enough to induce an increased production of the relevant GSH S-transferase. This may be due to the ability of fish to remove small amounts of Se from the water thus alleviating dietary Se deficiency. The GSH S-transferases of rainbow trout liver have not been as clearly characterized as those from rat but a number of differences have been shown to exist (Nimmo \& Clapp, 1979; Nimmo et al. 1981) which could infer differing abilities to metabolize hydroperoxides. Indeed of the three GSH S-transferases shown to be induced by Se deficiency in rat liver (Mehlert \& Diplock, 1985) only one has been found in trout liver (Nimmo et al. 1981).

If GSH S-transferase(s) are able to conjugate hydroperoxides (or intermediates involved in their formation) as they do other xenobiotics (Spearman et al. 1985) this would explain the capacity of these enzymes to inhibit malondialdehyde formation in the in vitro microsomal peroxidation system. Further investigations involving the GSH S-transferases and Se-deficiency may help to elucidate the role of GSH-metabolizing enzymes in the antioxidant protective mechanisms present in salmonid fishes.

These experiments help to verify previous observations with Se-deficient rainbow trout, namely that although hepatic GSH S-transferase activity increases in Se deficiency and although this will inhibit lipid peroxidation (as for example in in vitro systems) it does not do so by conventional peroxidase activity.

\section{REFERENCES}

Bell, J. G., Adron, J. W. \& Cowey, C. B. (1986a). Proceedings of the Nutrition Society 45, 42 A.

Bell, J. G., Cowey, C. B. \& Youngson, A. (1984). Biochimica et Biophysica Acta 795, 91-99.

Bell, J. G., Pirie, B. J. S., Adron, J. W. \& Cowey, C. B. (1986 b). British Journal of Nutrition 55, 305-311.

Burk, R. F., Nishiki, K., Lawrence, R. A. \& Chance, B. (1978). Journal of Biological Chemistry 253, 43-46.

Cathcart, R., Schwiers, E. \& Ames, B. N. (983). Analytical Biochemistry 134, 111-116.

Habig, W. H., Pabst, M. J. \& Jackoby, W. B. (1974). Journal of Biological Chemistry 249, 7130-7139.

Hasunuma, R., Ogawa, T. \& Kawanish, Y. (1982). Analytical Biochemistry 126, 242-245.

Hayashi, S. \& Ooshiro, Z. (1975). Bulletin of the Japanese Society of Scientific Fisheries 41, 791-796.

Lawrence, R. A. \& Burk, R. F. (1978). Journal of Nutrition 108, 21 1-215.

Lawrence, R. A., Parkhill, L. K. \& Burk, R. F. (1978), Journal of Nutrition 108, 981-987.

Lush, I. E., Cowey, C. B. \& Knox, D. (1969). Journal of Experimental Zoology 171, 105-118.

Mehlert, A. \& Diplock, A. T. (1985). Biochemical Journal 227, 823-831.

Meyer, D. J., Beale, D., Hong Tan, K., Coles, B. \& Ketterer, B. (1985) FEBS Letters 184, 139-143.

National Research Council (1981). Nutrient Requirements of Coldwater Fishes. Washington, DC: National Academy Press.

Nimmo, I. A. \& Clapp, J. B. (1979). Comparative Biochemistry and Physiology 63 B, 423-427.

Nimmo, I. A., Coghill, D. R., Hayes, J. D. \& Strange, R. C. (1981). Comparative Biochemistry and Physiology 68B, $579-584$.

Nishiki, K., Jamieson, D., Oshino, N. \& Chance, B. (1976). Biochemical Journal 160, 343-355.

Oshino, N. \& Chance, B. (1977). Biochemical Journal 162, 509-525. 
Prohaska, J. R. \& Ganther, H. E. (1977). Biochemical and Biophysical Research Communications 76, 437-445.

Sies, H. \& Summer, K. H. (1975). European Journal of Biochemistry 57, 503-512.

Spearman, M. E., Prough, R. A., Estabrook, R. W., Falck, J. R., Manna, S., Leibman, K. C., Murphy, R. C. \&

Capdevila, J. (1985). Archives of Biochemistry and Biophysics 242, 225-230.

Xia, Y., Hill, K. E. \& Burk, R. F. (1985). Journal of Nutrition 115, 733-742. 